\title{
Discourse and the study of organization: Toward a structurational perspective
}

\section{Loizos H eracleous and John Hendry}

\section{Editor's note}

This is a continuation of the discussion on the importance of social discourse initiated in the last issue. Further comments would be welcome.

Existing approaches to organizational discourse, which we label as 'managerialist', 'interpretive' and 'critical', either privilege agency at the expense of structure or the other way around. This tension reflects that between approaches to discourse in the social sciences more generally but is sharper in the organizational context, where discourse is typically temporally and contextually specific and imbued with attributions of instrumental intent. As the basis for a more sophisticated understanding of organizational discourse, we draw on the work of Giddens to develop a structurational conceptualization in which discourse is viewed as a duality of communicative actions and structural properties, recursively linked through the modality of actors' interpretive schemes. We conclude by exploring some of the theoretical implications of this conceptualization and its consequences for the methodology of organizational discourse analysis. 
The linguistic turn of the later 20th century has led to a widespread and growing interest in discourse, both in the social sciences generally and - the focus of this paper - in organization studies. In the late 1970s, organization scholars began to draw attention to the symbolic and metaphorical aspects of organizational discourse (M anning, 1979; Dandridge et al., 1980) and theory (M organ, 1980, 1983), and to the central role of language as a carrier of shared understanding in the creation and maintenance of organizational structures (Daft \& Wiginton, 1979; Pondy \& M itroff, 1979; Louis, 1983; Smircich, 1983). Subsequent scholars have adopted a wide range of approaches to the analysis of organizational discourse and have conceptualized discourse itself, and its relations to organizational behavior, in a variety of different ways (M umby \& Stohl, 1991; Grant et al., 1998). Three dominant approaches have, however, emerged, which we outline in this paper. Interpretive approaches conceptualize discourse as communicative action that is constructive of social and organizational reality. Instrumental or managerialist approaches view discourse as a tool at actors' disposal, for facilitating managerially relevant processes and outcomes such as effective leadership and organizational change. Critical approaches conceptualize discourse as power-knowledge relationships, constitutive of subjects' identities and of societal structures of domination.

This conceptual diversity can be related to a similar diversity of approaches to discourse in the social sciences more generally and reflects long-standing divisions between agent-centered and structuralist theories in sociology (Burrell \& M organ, 1979; Thompson, 1989). The interpretive and managerialist approaches privilege the action level, giving primacy to human agency and how agents can use discourse to shape their own or others' understandings of a situation, while the critical approach privileges the structural level, giving primacy to how human agency is constituted and may even be lost in the webs of discursive structures and the patterns of social domination that these structures surreptitiously help to legitimize and sustain.

When discourse is treated at a societal level, the tensions between structuralist and agent-centered perspectives can to a certain extent be bracketed out for the purpose of analysis. A traditional agent-centered analysis of a text, in terms of what the author intended or sought to communicate, and a structural or post-structural analysis, in which agency is effectively denied or suspended, need not impinge directly on each other. They address different issues and inhabit different worlds. In an organizational context, however, the author as intentional agent is ever present. Unlike, say, novels, organizational discourse tends to be both short-lived and highly context-specific. Even when fixed as text, it retains many of the properties associated by Ricoeur (1991) with speech acts, remaining closely bound to its authorial context and relying 
for its meaning on attributions of instrumental intent (Petty \& Cacioppo, 1986; Burgoon et al., 1994).

O rganization studies cannot afford simply to ignore the insights that might be afforded by structural perspectives on discourse, but if these are to be made relevant to the organizational context we shall need a conceptualization of discourse that can address considerations of both structure and action, as well as their dynamic interrelation, and that allows us to study and understand both the functional aspects of organizational communication and the deeper structural properties of discursive practices within organizational contexts. Drawing on the work of Giddens $(1979,1984,1987,1993)$ we develop in this paper a structurational conceptualization in which discourse is viewed as a duality of communicative actions and structural properties, recursively linked through the modality of actors' interpretive schemes.

We do not claim, or indeed aim, to fully resolve the tension between structure and agency in organizational discourse studies. Giddens's structuration theory has been criticized by numerous scholars from both structural and agency perspectives as reducing one perspective to the other or conflating rather than bridging the two (Callinicos, 1985; Willmott, 1986; Layder, 1987; Held \& Thompson, 1989; Johnson, 1990; Byrne, 1991; Archer, 1996; M estrovic, 1998), and we recognize that those criticisms will apply equally to our own work. Following Weaver and Gioia (1994) and Giddens himself (1984: 326), however, we would contend that the structurational perspective provides a valuable meta-theoretical device for comprehending the innate complexity of the world and the diversity of scholarly perspectives to which this gives rise, leading to a more sophisticated and productive view of organizational level discourse than can be obtained from any of the existing perspectives.

In the last part of the paper, we defend this contention by suggesting that the structurational view of discourse can facilitate cross-fertilization between different theoretical approaches and by showing how it can be used to extend an existing theoretical perspective such as the 'genre' perspective. We conclude by exploring the methodological implications of our view for organizational level discourse analysis.

\section{Approaches to discourse in organization theory}

The linguistic turn in the social sciences led to early calls for more complex understandings of organizations highlighting the role of language not only as an instrumental means of information exchange but also as constructive of social and organizational reality (Pondy \& M itroff, 1979; Dandridge et al., 
1980). O rganization theorists called for in-depth analyses of organizational discourses (M anning, 1979) and became interested in such issues as how language is intricately bound up with organization (D aft \& Wiginton, 1979) and how organization theory itself is implicitly constituted by metaphorical discourses that need to be made explicit (M organ, 1980, 1983).

Discourse analysis, in the broad sense of utilizing textual data in order to gain insights to particular phenomena, has had a rich and varied heritage in the social sciences, spanning the fields of sociology, anthropology, psychology, political science and history (O'Connor, 1995), and this same richness and diversity is evident in the organizational sciences. A pproaches utilized and expounded include hermeneutics (Kets de Vries \& M iller, 1987; Thachankary, 1992; Phillips \& Brown, 1993), ethnomethodology (Atkinson, 1988), rhetorical analysis (Keenoy, 1990; Alvesson, 1993; Watson, 1995), deconstruction (Kilduff, 1993; N oorderhaven, 1995), metaphorical analysis (O rtony, 1979; Lakoff \& Johnson, 1980), critical discourse analysis (Knights \& M organ, 1991, 1995; du Gay \& Salaman, 1992; van Dijk, 1993; Garnsey \& Rees, 1996), narrative analysis (M anning \& Cullum-Swan, 1994; Barry \& Elmes, 1997), and semiotic analysis (Barley, 1983; Fiol, 1989). Utilization of integrated methods drawing from more than one theoretical approach has been less common and more recent, but examples include the work of Gephart (1993) and O'Connor (1995).

Both discourse and related terms, such as language, text or narrative, have been conceptualized and categorized in diverse ways in organization theory (van Dijk, 1997; Grant et al., 1998). We propose, however, that these can be grouped within three main approaches which we call 'instrumental' or 'managerialist', the 'interpretive' and the 'critical', as discussed below. These approaches are not mutually exclusive, but they can be seen as significantly distinct approaches to the study of discourse. A key distinction made is that between interpretive and critical approaches to discourse (M umby \& Clair, 1997), which parallels the related distinction of research focusing on meaning construction processes or on issues of power (O swick et al., 1997), as well as the distinction between monological accounts presenting the perspective of a dominant group and dialogical accounts presenting a multiplicity of conflicting perspectives and multiple realities (Boje, 1991; K eenoy et al., 1997; Grant et al., 1998).

The interpretive approach: D iscourse as constructive of social reality

In the interpretive approach, language, as the basic building block of discourse, has been seen not merely as an instrumental means of information 
exchange but primarily as constructive, through its effects on actors' thoughts, interpretations and actions, of social and organizational reality. Both organization theory (Weick, 1977; Pondy \& M itroff, 1979) and the sociology of knowledge (Berger \& Luckmann, 1966; Ortony, 1979; M oscovici, 1981) have long recognized the constructive role of language in social life. After Pondy and M itroff's (1979) initial call for the development of more complex understandings of organizations, researchers began to focus on interpretive frameworks emphasizing the social construction of meaning and the central role of language as a symbolic medium in constructing social reality (Pettigrew, 1979; Dandridge et al., 1980; Pondy et al., 1983; Gray et al., 1985; Donnellon et al., 1986).

Studies from an interpretive perspective have illustrated how language used as a symbolic process is central to the development and sustainment of shared meanings (Smircich, 1983) and a common identity for organizational members (Evered, 1983). The guiding motivation of the approach is to gain an in-depth understanding of the role of language in meaning construction processes and to this end researchers have explored such elements or configurations of discourse as stories (M artin \& Powers, 1983; Boje, 1991; H ansen \& Kahnweiler, 1993; Boyce, 1995), humor (Rodrigues \& Collinson, 1995; $\mathrm{H}$ atch, 1997), and metaphor (Crider \& Cirillo, 1991; Tsoukas, 1991, 1993; Chilton \& Ilyin, 1993).

There would seem to be at the heart of the interpretive approach a fairly fundamental, if fruitful, contradiction. On the one hand, researchers draw on the concepts and language of agent-centered cognitive psychology to describe the ways in which meaning is structured. On the other hand, they draw heavily on ideas taken from the social constructionism of Berger and Luckmann (1966) and Garfinkel (1967) that would appear to support a discursive psychology completely at odds with the cognitivist position (Edwards, 1997). The overall thrust of the approach, however, would seem to be in line with the agent-centered hermeneutics of Ricoeur (1991). Hermeneutically, the R icoeurian 'speech act' captures both the intentionality of organizational discourse and the social context of its production and reception, but the latter features only as a resource for the creation and manifestation of meaning, not as a structural constraint on the possibility of meaning. O nce discourse becomes fixed in writing as 'text' and decontextualized from its situational, economic, social and cultural contexts, the text becomes open to various interpretations not necessarily related to what the author intended to say, and displays non-ostensive references projecting new possibilities for being-in-the-world (Ricoeur, 1991: 149). But the effect of this is not to deny authorial intent but rather to liberate the subject from current social structures and understandings by opening up, through placing 'oneself 
en route toward the orient of the text' (Ricoeur, 1991: 122), new possibilities for being. Discourse, from this perspective, is situated in the structures of being, not the other way around (Ricoeur, 1991: 68).

The managerialist approach: $D$ iscourse as a facilitator of managerially relevant outcomes

Building on the insights of the interpretive approach to discourse, as well as on insights from a variety of other disciplines, researchers in the managerialist tradition have focused on how language can be applied to the facilitation of managerially relevant processes and outcomes such as the exercise of leadership (Pondy, 1978; Westley \& M intzberg, 1989; Schein 1992), the emergence of effective strategies (Liedtka \& Rosenblum, 1996) and the management of organizational change (Johnson, 1987, 1990; Barrett et al., 1995; Ford \& Ford, 1995; Westley \& Vredenburg, 1996).

Ford and Ford (1995), for example, arguing that intentional change is based in and driven by particular types of linguistic communication, drew on speech act theory (A ustin, 1961) to analyze the change process and its breakdowns as a dynamic of conversations. Westley and Vredenburg (1996), drawing on theories of cultural change, focused on the need for a constant realignment of interpretation and action within intentionally managed change processes and explored the role of metaphor in mediating between these. Barrett et al. (1995), conceptualizing the change process in terms of the social construction of meaning, stressed in particular the importance of dialog as providing a medium for the evolution of language and consequent reconstruction of meaning within an organization. Various studies of the role of metaphor in facilitating organizational change (M organ \& R amirez, 1983; Pondy, 1983; Sackmann, 1989; Cleary \& Packard, 1992; M arshak, 1993) have highlighted the creative potential of metaphorical statements in enabling organizational actors to re-perceive reality in novel ways which can bridge the old state with the new.

$M$ any of these studies draw on aspects of the interpretive approach, but the emphasis is different. Whereas interpretive studies focus on the emergent effects of discourse on the actor as reader or listener, managerialist research follows traditional communication studies in focusing on how these effects might be manipulated by the author. The managerialist view thus emphasizes the instrumental use of language-based communication to achieve managerially relevant outcomes, with discourse (as a body of communicative actions) seen not so much as a medium for the social construction of meaning as a communicative tool at the actors' disposal. The guiding 
motivation is the facilitation of managerially relevant outcomes such as effective organizational change.

The critical approach: D iscourse as constitutive of structures of domination

The critical stream of research has applied radical conceptions of subjectivity and identity to the analysis of organizational texts (M umby \& Stohl, 1991) or other organizationally relevant discourses, including the discourses of work, management, corporate strategy and enterprise (Knights \& Willmott, 1989; Knights \& M organ, 1991; du Gay \& Salaman, 1992; du Gay et al., 1996). As for Foucault (1980), discourses are conceptualized by these researchers as power-knowledge relations that are linguistically communicated, historically located and embedded in social practice. Individual actors are in this view constituted as subjects by the effects of 'elite discourses' and other 'technologies of power': discourse 'invents and attempts to exercise a form of rule through the production of certain sorts of human subject' (du Gay \& Salaman, 1992: 628).

The critical approach to organizational discourse follows Foucault in insisting upon the decentering of the subject and the rejection of human agency as a determining influence upon discourse (Freundlieb, 1994). It is, rather, the discourse which determines and constitutes the subject's identity and rationality, and, far from discourse being a tool at the subject's disposal, as in the managerialist approach, the subject itself is seen as located and trapped in discursive structures (Foucault, 1972: 96, 131; 1991: 58). The guiding motivation of the critical approach is also diametrically opposed to that of 'orthodox' managerialist management research (Burrell \& M organ, 1979: 118), as it aspires to radical social change through the critical understanding of relations of social domination and their bases. In analyzing the discourses through which existing power structures and ideologies are enacted, reproduced and legitimated, critical discourse analysts seek to bring about their demystification and thus delegitimation (van Dijk, 1988, 1993; Wodak, 1990).

It is important to note that, quite apart from issues of structure and agency, the word discourse does not always signify the same thing. For writers in the interpretive and managerialist traditions, the word 'discourse', if used at all, is used either in its everyday sense as referring to a body of language-based communications or, occasionally, in an expanded sense to include non-linguistic as well as linguistic forms of symbolic communication. For writers in the critical tradition, the word refers to social structures of 
power-knowledge relations, and embraces both linguistic and non-linguistic communications and the social practices in which they are embedded. These differences cannot be ignored. If we are to develop an integrating perspective of organizational discourse, however, we shall need to settle on a definition of discourse that can be employed across the board. For this reason, we shall restrict our attention in this paper to the linguistic aspect and define discourse as any body of language-based communicative actions, or language in use. Following Ricoeur (1971) and consistent with Giddens (1979) we shall also use the word 'text' in its linguistic sense to mean discourse fixed in writing. Of course, in adopting these definitions, we do not wish to play down the importance of symbolic communication or of those features of organization that might be captured by more comprehensive, metaphorical uses of the term 'text' (Geertz, 1973; K ets de Vries \& M iller, 1987; Thachankary, 1992; Phillips \& Brown, 1993; Putnam et al., 1996). Nor do we wish to deny the importance of those structural features of social organization on which the critical researchers have focused. But these can be called by other names, and to include them in our definitions would only cause confusion and detract attention away from our central concern with structure and agency.

Interpretive and managerialist conceptualizations of discourse have proved immensely valuable, but in privileging the action level they have constrained researchers from exploring the deeper discursive and social structures in which both communicator and receiver are situated, on which the very possibility of intentional communication depends, and through which that possibility is both enabled and constrained. The critical conceptualization of discourse as socially embedded power-knowledge relationships is much more sensitive to these aspects of social structure and context, but its decentering of the subject leaves no place for the individual as an active agent and affords no prospect of relating the structural level to the primary concerns of managers or mainstream management scholars.

In the next section, we develop a structurational view of discourse that can address both the action and the structure levels and their dynamic interrelation, based on the work of Anthony Giddens (1979, 1984, 1987, 1993), and especially his theory of structuration $(1979,1984)$. Giddens has written relatively little about discourse, which has not been developed as a central construct in his theory (Gadacz, 1987), but he has done more than anyone to integrate structure and agency within a single conceptual framework (Thompson, 1989). Based on structuration theory, we develop a definition of discourse as a duality constituted by two dynamically interrelated levels: the surface level of communicative action, and the deeper level of discursive structures, recursively linked through the modality of actors' interpretive schemes. This view of discourse goes beyond understandings of discourse 
that focus on either structure or action and advance a monolithic view of the relationship between discourse and the subject, being able to encompass the interrelated action/structure levels and to offer a more sophisticated view of the discourse-subject relationship. The theoretical implications and contributions of this view are developed in detail in the final section of the paper.

\section{Giddens's theoretical project and views on discourse}

\section{Giddens's theoretical project and its use in organizational research}

A fundamental theme underlying Giddens's work is the rejection of a whole range of dualisms that have characterized social thought, especially the dualism of structure and agency, and the reformulation of such dualisms in terms of dualities. He sees interpretative sociologies as 'strong on action but weak on structure', and functionalist and structuralist sociologies as 'strong on structure but weak on action' (Giddens, 1993: 4). The concept of the 'duality of structure', central to Giddens's theoretical scheme, emphasizes that 'social structure is both constituted by human agency and yet is at the same time the very medium of this constitution' (Giddens, 1993: 128-9, emphasis in original). Daily practices such as communicative actions are the main substantive form of the dimensions of the duality of structure, which is instantiated, reproduced and potentially changed through such practices (Giddens, 1984: 36). ${ }^{1}$ D aily practices are thus implicated in continuous processes of structuration, 'the structuring of social relations across time and space' (Giddens, 1984: 376). A dequate understanding of structurational processes entails in-depth involvement in the routinized, daily interactions of knowledgeable agents in order to discover the conditions influencing the continuity or change of social and organizational structures (Giddens, 1984: 25).

Giddens's work can be located in the theoretical tradition that aims to transcend the structure-agency dualism and to reconcile interpretive and functionalist sociological views, in common with the work of such theorists as Bhaskar (1979), Bourdieu (1977), and Silverman (1970). Each of these approaches is different, but they all share the concern of bridging the gap between action and structure in social life, the recognition that, in the study of social systems, understanding individual actors' meaning is of paramount importance, and the proposition that meaning, and therefore social reality, is constructed, sustained and changed through social interaction.

Although the use of Giddens's work by organizational researchers has been selective (W hittington, 1992), structuration theory has had a significant influence in organizational research, both in its own right and through its 
application to the concept of organizational structure developed by $R$ anson et al. (1980). Structuration theory has been used both as a meta-theory that can enable multi-paradigmatic inquiry without resorting to paradigm incommensurability (Weaver \& Gioia, 1994) and as a useful complement to institutional theory that can add a much-needed process perspective on the link between institutions and actions (Barley \& Tolbert, 1997). It has also been applied to more specific areas, including the study of politics as an aspect of organizational culture (Riley, 1983), the development of a deeper understanding of the role of advanced information technologies in organizational change (DeSanctis \& Poole, 1994), the development of a conceptual model of organizational transformation (Sarason, 1995), the integration of individual leadership and social elite theory perspectives on business leadership (Whittington, 1993), the expansion of the scope of management accounting research from a primarily technical focus to include sociopolitical issues (M acintosh \& Scapens, 1990), and to the development of new perspectives in communication research such as the 'genre' perspective (Yates \& Orlikowski, 1992; Orlikowski \& Yates, 1994).

These applications of structuration theory have often generated lively responses and debates, from the initial response to Ranson et al. (1980) by Willmott (1981), to the protracted exchange prompted by the $M$ acintosh and Scapens (1990) work (Boland, 1993, 1996; Scapens \& M acintosh, 1996), and a consideration of the organizational literature that has utilized the theory of structuration for theory development and empirical analysis reveals considerable diversity in both interpretations and applications of the theory (Jones, 1999). At the risk of oversimplification of a complex set of concepts we can, how ever, say that a structurational view of organizations at the very least entails the following: a focus on both observable action and the deeper structures that guide action, and a recognition of their dynamic interrelation; a view of social structures as rules and resources drawn on in everyday interaction, shaping but not deterministic of human agency; an understanding that structures can thus be reproduced or potentially changed through interaction and over time; and a treatment of people as active, knowledgeable agents who reflexively monitor their situation as opposed to being 'structural dopes' determined by social structures.

Giddens on discourse, language and structuralism

\section{Giddens on discourse}

Although the concept of discourse has not played a central role in Giddens's work, it has arisen in three separate contexts. Firstly, in the context of Giddens's distinction between 'practical' and 'discursive consciousness', 
discursive consciousness refers to what actors are able to say about social conditions and the conditions of their own actions. Discourse, accordingly, is "what actors are able to "talk about" and in what manner or guise they are able to talk about it' (Giddens, 1979: 73). Secondly, in the context of Giddens's discussion of ideology and consciousness, discourse is seen as ideology in its most 'conscious' and 'superficial' form, involving the direct manipulation of communication by dominant classes to further their own interests (Giddens, 1979: 190-3). Thirdly, and most fundamentally, discourse plays a role in the social positioning of actors. According to Giddens, agents are positioned or situated in time-space, as well as socially within a network of social relations. Their social position is constituted within structures of signification, domination and legitimation, within which social interaction takes place. Giddens maintains that the knowledgeability incorporated in practical activities is a primary constitutive feature of the social world. Knowledge, in this context, is seen as accurate or valid awareness that exists at both the discursive and practical levels, and discourse is accordingly seen as a mode of articulation of such knowledge (Giddens, 1984: 83-92).

\section{Giddens on language}

Giddens has displayed his views on language on several occasions in his work. He holds a constructive view of language as not just a means of information exchange, but also as constitutive of social life (Giddens, 1984: xvi) through its nature as a medium of practical, recursive social activity (Giddens, 1993: 25). Language is thus a medium of not only communication, but also characterization or typification (Giddens, 1993: 54). Giddens also refers to language as an apt example of his concept of 'duality of structure', which holds that social structures are both medium and outcome of human agency (Giddens, 1984). The rules of language are constantly evoked in the course of daily activities, and 'enter into the structuring of the texture of everyday life' (Giddens, 1984: 22). But linguistic rules and language as a structure exist only in so far as they are manifested in daily communicative actions (Giddens, 1993: 129) and this use is enabled by the nature of language rules as interpretive schemes located in agents' practical consciousness (Giddens, 1984: 48).

Giddens's work stresses the context-dependence of practical activities, including the use of language: 'context dependence ... is aptly regarded as integral to the production or meaning in interaction, not as an embarrassment to formal analysis ... Interaction ... is temporally and spatially situated' (Giddens, 1993: 111). As an example of context-dependence in operation, Giddens draws attention to the fact that we can only understand 
seeming contradictions in linguistic utterances such as irony or sarcasm through an awareness of their context (Giddens, 1993: 154-5).

Giddens's views on language are also apparent in his trenchant critique of the structuralist tradition, ${ }^{2}$ outlined below. Through this critique, Giddens emphasizes the need for considering the social-cultural context of texts in textual interpretation, that meaning arises not only from textual content but also from how the content relates to this context, viewing people as knowledgeable agents and competent users of language, and emphasizing the importance of temporality in textual interpretation.

\section{G iddens's critique of structuralism}

Giddens believes that, although structuralism has brought to the fore of social theory key issues such as the importance of temporality as reversible time, the properties of signification systems as existing outside time-space, and the relevance of decentering the subject, it is fraught with vast theoretical difficulties which make structuralism an unsuitable theoretical tradition through which the themes it has highlighted can be pursued (Giddens, 1979; 1987).

De Saussure's (1983) basic distinction between langue and parole, and the emphasis on langue, is deemed as inadequate because it has isolated language from its social environments of use and therefore does not promote the need for a theory of the competent speaker or language-user (Giddens, 1979). As a result, a conception of human subjects as agents has not been reached in structuralism, and the theoretically decentered elements (such as the author) are not satisfactorily recombined in the analysis (Giddens, 1987).

Furthermore, because of the stress on form rather than substance, and of the thesis of the arbitrary character of the sign (de Saussure, 1983), structuralism has promoted a 'retreat into the code', where the aim was 'to determine the forces operating permanently and universally in all languages, and to formulate general laws which account for all particular linguistic phenomena historically attested' (de Saussure, 1983: 6). This 'retreat into the code' meant that structuralism has been unable to provide satisfactory accounts of reference, or of meaning. $M$ eaning, for example, is said to derive from the intra- or inter-textual play of differences of the signifiers, ignoring the relationship of such signifiers with their contexts of use (Giddens, 1987). The focus on the signifier/signified distinction as arbitrary has led to an elision between the 'signified' and the 'object signified', the reality to which the sign is related (Giddens, 1979).

Lastly, de Saussure's theoretical distinction between synchrony and 
diachrony has been utilized by structuralism as a methodological division, which is deemed unjustifiable because of the fact that it is not possible to study and understand linguistic or social systems in abstraction from change (Lewin, 1952). The general 'repression of time' in social theory has been attributed to the maintenance of this distinction between synchrony and diachrony or statics and dynamics (Giddens, 1979).

Toward a structurational view of discourse

Giddens's views on discourse and language are scattered throughout his writings. Although there are common threads, he has not developed a framework that can systematically address both the levels of communicative action and structural features of discourse, and highlight their dynamic interrelations mediated by agents' interpretive schemes. In what follows, we attempt to remedy this deficiency, utilizing Giddens's theory of structuration to develop such a framework. We complement our arguments and expand the insights afforded by structuration theory by drawing from hermeneutically oriented work within the fields of cultural anthropology (e.g. Bateson, 1972), ethnography (e.g. Frake, 1964; van M aanen, 1973), socio-cognitive linguistics (e.g. van Dijk, 1988; M cCann \& Higgins, 1990; Saferstein, 1992), cognitive psychology (e.g. M oscovici, 1981; Taylor \& Crocker, 1981; Rumelhart, 1984), organizational cognition (e.g. Weick, 1979; Gioia, 1986a, 1986b) and interpretive sociology (e.g. Berger \& Luckmann, 1966) as appropriate. In order to clarify certain theoretical aspects of the structurational view of discourse proposed, we also contrast our views of discourse with those of structuralist and post-structuralist authors such as Barthes (1994) or Foucault (1972).

\section{A structurational view of discourse}

In the same way that social systems do not have structures but exhibit structural properties (Giddens, 1984), discourses can also be seen as not having structures but as exhibiting structural properties that are implicit, intertextual, trans-temporal and trans-situational. As the structural properties of social systems are instantiated as social practices and as memory traces orienting agents' conduct (Giddens, 1984: 17), so the structural properties of discourse are instantiated in social interaction at the communicative level through the modality of agents' interpretive schemes. The two levels of discursive structures and communicative action are thus analytically distinct but practically interrelated, as represented in Figure 1, adapted from Giddens (1984: 29). For the purposes of this section, we bracket out structures of 


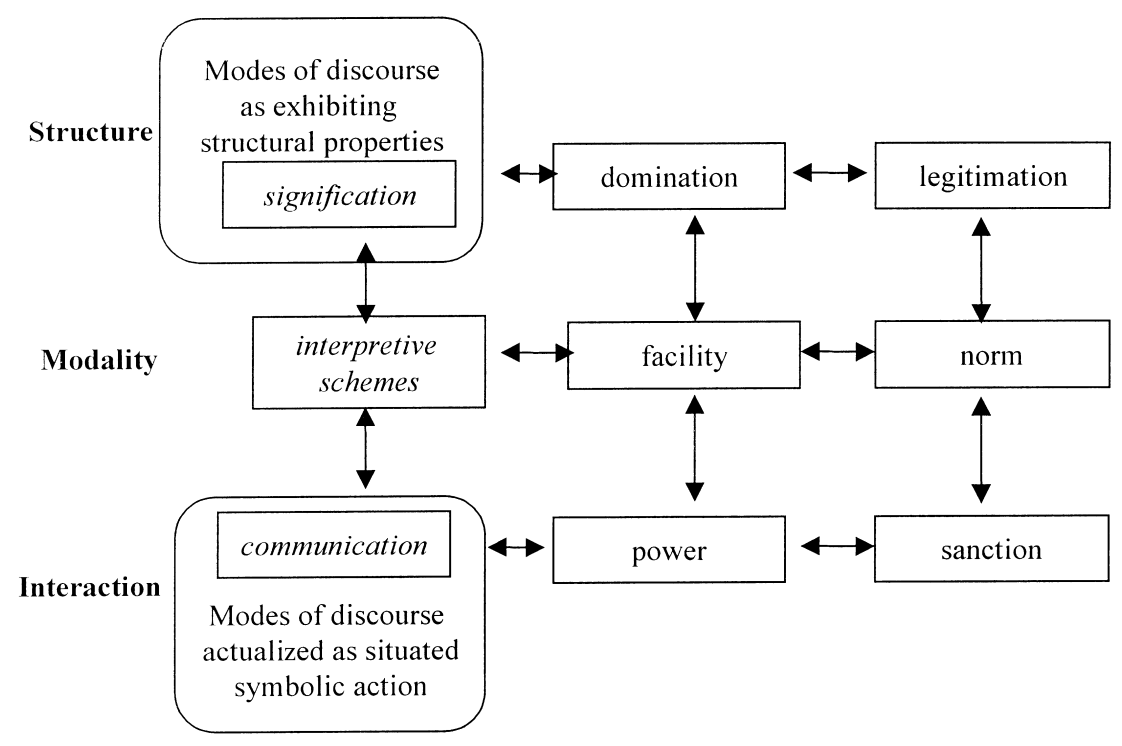

Figure 1 Discourse and structuration theory Source: Adapted from Giddens (1984).

domination and legitimation, and focus on the structures of signification, interpretive schemes and communicative action, since these are the main elements of the structuration of social life most relevant to symbolic orders such as modes of discourse (Giddens, 1984: 33).

The communicative manifestations of structural features of discourse point to the fact that these features are both enabling and constraining. Actors 'know' in their 'practical consciousness' (Giddens, 1984: 44) that specific modes of discourse must be employed in particular contexts in order for their opinions, ideas, or argumentations to be seen as legitimate and worth attention. Discursive structural features are thus used as a resource for effective argumentation which is characterized by a 'seeming' probability, what actors in a social context believe to be the case and not necessarily what is the case (cf. Aristotle, 1991).

The communicative level: $D$ iscourse as situated symbolic action

From a structurational viewpoint, discourse at the communicative level is constituted of communicative acts. A communicative act is defined as an action 'in which an actor's purpose, or one of an actor's purposes, is linked to the achievement of passing on information to others' (Giddens, 1993: 94; 
cf. Austin, 1961). From a structurational perspective, discourse, at this level, is communicative (inter)action which draws from structures of signification through actors' interpretive schemes (Giddens, 1984). In this sense, discourse as action arises out of the subjective meanings which individuals attach to situations and which orient their actions (Weber, 1991), as active agents pursuing their perceived interests in specific contexts (Blumer, 1970). The view of discourse as situated symbolic action assumes that utterances not only say things, but also do things; discourse is, thus, in a fundamental sense, action (O swick et al., 1997).

In structuralism, meaning is said to derive from internal relations among signifiers (de Saussure, 1983) and in post-structuralist approaches such as the later Barthes (1977: 155-64), it resides in inter-textual networks and can be created and recreated by active experiencing of the text. From an interpretive viewpoint, however, which structuration theory adopts through its conceptualization of human agency as knowledgeable and reflective (Giddens, 1993), meaning derives from the interaction of signifiers within a hierarchy of contexts: 'The word is the context of the phoneme. But the word only exists as such - only has "meaning" - in the larger context of the utterance, which again has meaning only in a relationship. This hierarchy of contexts within contexts is universal for the communicational (or "emic") aspect of phenomena ...' (Bateson, 1972: 408, emphasis in original). The contexts shaping the meaning of communicative actions include the semantic context (Rumelhart, 1984; Eysenck, 1993), the situational and organizational contexts (Goffman, 1972; Donnellon, 1986; Schultz, 1991; Saferstein, 1992) and the societal context (H ofstede, 1985).

Contrary to (post)structuralist thought, from a structurational viewpoint, signification is thus not the outcome of relations in the intra- or intertextual domains, but arises from the interaction of these domains with settings of practical action (Giddens, 1987: 99). Giddens's approach to understanding human agency, accordingly, gives primary importance to such features as 'practical consciousness' (what actors know or believe about social conditions and their own actions, but cannot express discursively) and the contextuality of action (the situated character of interaction in time-space), features which are absent or downplayed in structuralist accounts (Giddens, 1987: 98).

This situated character of communication has been emphasized by ethnographic research that has assumed that language and social reality are interrelated and that a description of the context of communication is vital in understanding language use. Ethnographers have accordingly emphasized the cultural and situational determinants of communicative legitimacy or appropriateness (Frake, 1964; M alinowski, 1970; van M aanen, 1973). The 
symbolic nature of communication, in addition, has been elucidated by studies from a psycho-linguistic perspective. In this view, ordinary argumentations and explanations are seen as speech actions that have their sociocognitive correlates occur on the basis of shared representations and are active discursive constructions of reality (M CCann \& Higgins, 1990; X u, 1992). From a structurational viewpoint, such underlying socio-cultural beliefs and ideologies, as well as perceptions of communicative appropriateness, are not only mirrored, but also constituted, reproduced, and potentially changed through communicative actions.

The structural level: discursive and social structures

The concept of 'deep structures' is key to a fuller understanding of social and natural systems at various levels of analysis (Light, 1979; Gersick, 1991). Deep structures are stable, largely implicit, and continually recurring processes and patterns that underlie and guide surface, observable events and actions. The interpretation and use of the concept of deep structure vary in different theoretical domains. In the domain of discourse, we have approached deep structures as persistent features of discourse which transcend individual texts, speakers or authors, situational contexts and communicative actions, and pervade bodies of communicative action as a whole and in the long term. Such structural features include the central themes that hermeneutic researchers seek to uncover (Kets de Vries \& M iller, 1987; Thachankary, 1992), the root or generative metaphors that interpretive researchers have addressed (Schon, 1979; Pondy, 1983) and the rhetorical strategies in particular social contexts that rhetoricians aim to elucidate (K amoche, 1995; H opkins \& R eicher, 1997). These are structural features of discourses because they pertain to bodies of communicative actions or texts as a whole, persist over time, in a variety of situational contexts, and in communicative actions or texts produced by different actors. In addition, they are most often implicit as opposed to explicitly stated in texts and communicative actions, and are constructive of the subjects they are about, in line with a constructive view of language.

Lastly, both communicative actions and discursive structures are systematic, contextually located and linked to power relationships, ideologies and institutions, although in different ways. Communicative actions and texts, for example, aresystematic in that they obey linguistic rules and belong to a commonly accepted system of grammar within a community; discursive structures, on the other hand, are systematic in the sense that, within local contexts of use characterized by distinct cultures and practices, they may exhibit features such as systematic cross-metaphor coherence (Lakoff \& 
Johnson, 1980: 87-105), or thematic unity of what may at the surface appear as diverse and disconnected themes (Kets de Vries \& Miller, 1987; Thachankary, 1992). Similarly, communicative actions and texts are located within embedded semantic, situational, organizational and societal contexts, and discursive structures are, from a cognitive viewpoint, located in interpretive schemes which are themselves located contextually within other interpretive schemes, given the hierarchical structuring of cognition (Eysenck, 1993). Lastly, features of communicative texts and actions which support, perpetuate or potentially challenge established ideologies and power relations are the instantiations of deeper discursive structures pertaining to dominant elites or marginal groups (van Dijk, 1988); and in this sense both communicative actions and discursive structures are linked with wider social structures.

\begin{tabular}{|l|l|}
\hline Communicative level & Structural level \\
\hline Intra-textual & Inter-textual \\
Specific point in time & Longitudinal \\
Functional & Constructive \\
Situational & Transcends the situation \\
Explicit & Implicit \\
\hline & \\
& Common features \\
& Systematic \\
& \\
& Contextually located \\
& inked to power relationships, \\
&
\end{tabular}

Figure 2 Features of the structural and communicative levels of discourse 
The nature of the linkages of discourse with wider social structures is important. In structuralist approaches such as Foucault's (1972), subjects' actions and even their reason are seen to be determined by anterior discursive structures. 0 ur use of 'structures' here is, how ever, a structurational and not a structuralist one. For Giddens, structures are the rules and resources that actors draw on in their daily practices. In this sense, structures have no existence other than their instantiation in action and as memory traces (or interpretive schemes) orienting agents' conduct (Giddens, 1984). From a structurational perspective, therefore, social structures and the discursive structures they are linked to are not separate from and determinative of human actions, but are both the medium and the outcome of such actions (Giddens, 1984). On the one hand, discursive structures cannot be seen simply as the tools of intentional agents, since agency itself is influenced (but not determined) by these structures and the power-knowledge relationships and institutional structures with which they are bound up. On the other hand, discursive structures and social structures cannot be seen as fully determinative of individuals, who remain agents who could choose to do otherwise (Giddens, 1993: 81), taking within the constraints imposed by structure a potentially active, self-reflective role in the construction of the social reality of their group.

\section{D iscourse and interpretation}

For a complete treatment of the relationship between discursive structures and communicative action we would need not only a sociology, such as that of structuration, but also a psychology. The detailed development of such a psychology lies well beyond the scope of this paper, but some observations are in order.

Unsurprisingly, psychological theories exhibit much the same tensions and dichotomies as sociological theories. Traditional cognitive psychology, with its essentially closed conception of the mind, privileges the individual actor and seems to have little place, in its rigorous formulations, for the structural aspects of discourse. Discursive psychology, on the other hand, appears to have no place for intentional agency (Edwards, 1997). Hendry (forthcoming) has suggested that the psychological theory best fitted to a structurational view of discourse is Harré and Gillett's (1994) discourse psychology, in which intentional agency is retained but can be realized only through the medium of a mind which, as in more extreme forms of discursive psychology, appears as a social construction fashioned from the discourses in which the actor participates.

The details of such a psychology have yet to be worked out. M eanwhile, 
however, we can perhaps gain some understanding of the processes involved by drawing on cognitivist theories of social cognition and especially on the ways in which cognitive psychology has been adapted by researchers within the interpretive approach to organization studies. As noted earlier, there would seem to be a fundamental contradiction in the way these approaches use the concepts of individual cognitive psychology to explore the social construction of meaning. The effect of this, however, has been to extend the application of cognitive psychology so as to engage with the social and structural levels.

The key concept in this approach is that of schema. O riginally developed by $\mathrm{H}$ ead (1926) and Bartlett (1932), this has since become a central construct of cognitive psychology (Taylor \& Crocker, 1981; Rumelhart, 1984) and can be defined as 'a cognitive structure that consists in part of the representation of some stimulus domain. The schema contains general knowledge about that domain, including a specification of the relationships among its attributes, as well as specific examples or instances of the stimulus domain' (Taylor \& Crocker, 1981: 91). A schema can thus be seen as a psychological frame (Bateson, 1972: 186) providing the cognitive structuring necessary for actors to construct workable cognitive representations of the world and for consistency among cognitive elements and between these cognitive elements and actions (Festinger, 1959). Schemata can operate at various levels of detail or abstraction, and can be both evaluative, as in the case of attitudes, as well as descriptive. Schemata therefore have basic and vital functions in the interpretation of experience and indication of appropriate action (Taylor \& Crocker, 1981).

The concept of cognitive schemata at the organization level (Bougon et al., 1977; Weick, 1979), and the related concept of interpretive schemes (Bartunek, 1984; Bartunek \& M och, 1987; D ougherty, 1992) have long been incorporated in organization theory and various ways of conceptualizing and mapping cognitive maps have progressively been developed (H uff, 1990; Eden, 1992).

We follow Giddens (1984: 29) in defining interpretive schemes as 'the modes of typification incorporated within actors' stocks of knowledge, applied reflexively in the sustaining of communication'. From a structurational view of discourse, interpretive schemes are the modality through which discursive structures are instantiated at the level of communicative interaction, and through which communicative interaction can reproduce or challenge such structures.

This interaction is central to the construction of social reality and thus to agents' actions based on this reality, as emphasized by interpretive approaches to the sociology of knowledge (Berger \& Luckmann, 1966; 
M oscovici, 1981), which see language as the most important sign system of human society, objectifying and typifying experiences and meanings in the 'here and now'. In this view, language assumes symbolic significance, being capable of building up semantic fields or zones of meaning and thus social reality (Berger \& Luckmann, 1966: 49-61).

Gioia (1986a) elucidates the structurational process between interpretive schemes and discourse (as communicative action exhibiting structural properties), as follows: 'Understanding is accomplished and communicated mainly by means of symbols (most notably in the form of metaphorical language) that are then retained in a structured or schematic form via scripts. The scripts subsequently serve as a basis for action that further facilitates the meaning construction and sensemaking processes' (Gioia, 1986a: 50). In a fundamental sense, cognitive structures are symbolic in nature, since they are mental representations of experience and knowledge stored in memory (Gioia, 1986a). Symbols, including communicative action, are integrated into individuals' cognitive structures when they are interpreted through them and connected with existing ideas and beliefs (Eoyang, 1983: 113). A structurational view emphasizes the malleable nature of interpretive schemes, which can progressively be re-defined through the addition and attrition of concepts, the transformation of perceived causal associations, and the altered salience of concepts (Eoyang, 1983), through individuals' learning from new experiences, actions or introspection.

Language influences not only the functioning of existing schemata, but also the development of their parameters. During cognitive development, schemata are constructed and reconstructed to meet the requirements of linguistic labels, and, during communication or even during actors' reflections, linguistic terms evoke these schemata which are essentially carriers of meaning. O nce schemata are developed, they are used as tools of thought without exerting more cognitive energy than is required in making use of their simpler components (Bloom, 1981; Donnellon, 1986).

Indicating the vital influence of interpretive schemes on action, Weick (1977) has suggested that people 'act out and real-ize their ideas', collectively creating their own realities. Individuals' actions are based on their definitions of the situation, whether or not these definitions correspond to the situation's more objective features (Thomas \& Thomas, 1970). Interpretive schemes and agents' (communicative) actions are thus interrelated in a continual dialectic fashion: action arises out of interpretive schemes, and new experiences or reflections influence interpretive schemes and thus subsequent action (Gioia, 1986a, 1986b). 


\section{Contributions and implications of a structurational view of discourse}

In this article, we began by exploring approaches to discourse in organization theory and suggesting that they are based on partial understandings of the nature of discourse and its relation to the subject, mirroring long-standing divisions in social science between approaches privileging either the acting subject or overarching societal structures. We then developed a structurational view of discourse, where discourse is seen as a duality of communicative actions and structural properties, recursively linked through the modality of actors' interpretive schemes. We do not claim that such a view of discourse can fully integrate the conflicting ideological positions often associated with (post)structural and agent-centered perspectives. We do propose, however, that a structurational view of discourse offers a sophisticated approach which can address a plurality of aspects of the nature and operations of discourse and place in context alternative views, enrich the understanding of the interrelations between discourse and the acting subject, and extend current theoretical perspectives in the study of organizations in potentially fruitful directions.

The theoretical contributions and implications of this development relate to its usefulness in placing alternative approaches in context and aiding cross-fertilization between domains; extending current theoretical perspectives; and indicating methodological directions for discourse analyses that take structuration seriously.

Placing alternative approaches in context and aiding crossfertilization between domains

Although organization theorists are now more willing to acknowledge the interrelationship between actors and institutions, the theoretical and methodological implications of this realization have only begun to be addressed (Barley \& Tolbert, 1997: 94). We view the development of a structurational view of discourse as a significant theoretical contribution in this direction. This theoretical conception of discourse can be located in the stream of work that has sought to utilize and apply structuration theory in ways that transcend diverse and parochial perspectives by accommodating them in a more sophisticated meta-theoretical framework (Ranson et al., 1980; Weaver \& Gioia, 1994), and responds to calls for further integration betw een organization theory and discourse-related perspectives ( $Z$ ald, 1996). In this spirit, the structurational view of discourse developed here contributes to the bridging of the long-standing chasm in the social sciences between 
approaches privileging structure or action, by elucidating how a key process, communicative (inter)action, is dialectically related to discursive and social structures through the modality of actors' interpretive schemes.

A structurational view also places alternative approaches to discourse in context. In the context of the metaphorical nature of scientific inquiry (van M aanen, 1979; M organ, 1980, 1983), alternative approaches to discourse highlight some aspects of the phenomenon and hide others (Lakoff \& Johnson, 1980). Interpretive approaches to discourse highlight the role of discourse in the construction of social reality and the role of the acting agent in this process, and managerialist approaches emphasize the intentionality of the acting agent in using discourse to facilitate managerially relevant outcomes, but both tend to downplay or ignore the links of the structural features of discourse with societal structures of domination. Critical approaches emphasize these links, but downplay or ignore the role of the acting subject in using discourse to achieve functional outcomes, or in developing shared meanings within local organizational contexts. In addition, none of these approaches has developed a comprehensive understanding of the role of interpretive schemes as a modality between the action and structure levels. A structurational view of discourse offers an encompassing framework which can accommodate these diverse perspectives and place them in the context of other, complementary perspectives. This can facilitate theoretical crossfertilization, and reduce the tendency of seeing such issues as the discourse-subject relation in uni-dimensional terms.

\section{Extending current theoretical perspectives}

A structurational view of discourse can also extend current theoretical perspectives through a combination of its insights with the existing theory. We illustrate this with reference to the 'genre' perspective of organizational communication and to perceptions of the discourse-subject interface.

The genre perspective of organizational communication (Yates \& Orlikowski, 1992; Orlikowski \& Yates, 1994) is informed by the theory of structuration. A 'genre' is defined as a 'typified communicative action invoked in response to a recurrent situation' (Yates \& Orlikowski, 1992: 301), examples being memos, proposals or meetings. Genres are enacted through 'genre rules', which 'associate appropriate elements of form and substance with certain recurrent situations' (Yates \& Orlikowski, 1992: 302). A structurational view of discourse extends the genre perspective in two important ways.

Firstly, it draws attention to discursive structures such as central themes, root metaphors or rhetorical strategies, which are instantiated in communicative actions that cut across genres of organizational communication, in this 
way providing linkages across apparently diverse genres. For example, a particular rhetorical strategy or central theme can be used in several different genres such as meetings, speeches, or memos. In this sense, discursive structures are enacted through and across genres, adding a useful lens for exploring the linkages and interrelationships across genres, and between genres and their social context.

Secondly, a structurational view of discourse draws attention to an additional type of rules to genre rules, involved in genre enactment. By highlighting the fact that particular communicative actions draw from discursive structures of communicational legitimacy or appropriateness in local organizational contexts, a structurational view suggests that genres are enacted not only through genre rules, but also through discursive structures that cut across genres within a particular social or organizational context. Identifying such discursive structures and relating them to genre rules would enhance a researcher's understanding of the local context, as well as processes of communicative interaction in that context.

Turning to perceptions of the discourse-subject interface, the approaches to discourse in social and organization theory discussed involve diverse understandings of the relationship between discourse and the subject. ${ }^{3} \mathrm{C}$ ritical approaches in organization theory see the subject's identity and rationality as constituted by discourses of social domination, thus having little or no place for knowledgeable and intentional human agency. $M$ anagerialist approaches emphasize the acting subject as a free agent, using communicative actions to achieve functional outcomes, largely ignoring the constraining effects of existing discursive and social structures. Interpretive approaches emphasize the social construction of reality through communicative action, but often downplay the potential of intentional and knowledgeable agency in influencing this construction of reality, seeking description rather than prescription.

A structurational view of discourse portrays the subject as both constrained and enabled by existing structures of signification, legitimation and domination. Giddens's discussions of agency emphasize that an individual could have acted otherwise, that the world does not hold a pre-determined future, and that agents' purposive conduct (such as communicative action) involves the application of knowledge to achieve certain outcomes ( $G$ iddens, 1993). A gents' choices may be constrained by existing structures, but are not determined by them. From a structurational perspective, therefore, agents can, through purposive communicative action, achieve functional outcomes (managerialist view) within a socially constructed reality (interpretive view), and, in so doing, potentially challenge and ultimately transform entrenched societal structures (critical view). 
Taking structuration seriously: Methodo logical implications for organizational discourse analysis

The most significant implications of our perspective are, in our view, for the methodology of organizational discourse analysis. A discourse analysis approach that takes structuration seriously needs to adequately address both context and temporality in the analysis; and to be able to go beyond explicit communicative actions to identify and track over time discursive structural features and link them theoretically to wider social structures.

Even though the need to address context and temporality sounds relatively uncontentious, inadequate consideration of these aspects has been a persistent issue in discourse analysis. A ccording to Cicourel, for example, 'the study of discourse and the larger context of social interaction requires explicit reference to a broader organizational setting and aspects of cultural beliefs often ignored by students of discourse' (Cicourel, 1981: 102). As Fairclough has observed, moreover, 'analysis of text is perceived as frequently proceeding with scant attention to context ... discourse analysis needs a developed sense of and systematic approach to both context and text' (Fairclough, 1992: 212-13, emphasis in original).

Even approaches which began with interpretive/hermeneutic inspirations, such as ethnomethodology, stressing features of language such as indexicality (the notion that language use and interpretation depend on contextual features) and the temporality of social activity (where social action is understood and analyzed with regard to its temporal location), have gradually adopted a more behaviorist orientation, effectively hindering them from grasping the richness of social life (Atkinson, 1988).

A dequate consideration of textual context calls for a hermeneutic anaIytical orientation. Contrary to structuralist approaches, hermeneutically inspired analyses emphasize the interpretive need of grasping other forms of life through researchers' immersion into them, and interpreting texts in the light of ethnographic data gathered longitudinally (Giddens, 1987, 1993). Texts should be studied as 'the concrete medium and outcome of a process of production, reflexively monitored by its author or reader'. Inquiry into this productive process involves exploring the author's or speaker's intentions as well as the practical knowledge involved in writing or speaking with a certain style for a particular audience (Giddens, 1979: 43). Interpretive accuracy of texts can thus be improved with inquiry in the settings of production of the text, the intellectual resources the author has drawn on and the characteristics of the audience it is addressed to (Giddens, 1987: 106). W hat is required of researchers at the methodological plane, therefore, is to immerse themselves in other forms of life, and to acquire the mutual knowledge required 
to sustain encounters and to converse with the 'natives' (Geertz, 1973; Giddens, 1993: 156-7).

A dequate attention to temporality calls firstly for a clear definition of what exactly it means. The concept of temporality has been variously understood by theorists. In Barthes's structuralism, for example, 'temporality is only a structural class of narrative (of discourse) . . . from the point of view of the narrative, what we call time does not exist ...' (Barthes, 1994: 112). In conversation analysis, the concept of 'temporal organization' of utterances refers to the timing or sequencing of particular utterances within conversations, how this influences the meaning of what is said and what it indicates about the speakers and their interrelationships (Pomerantz \& Fehr, 1997). In rhetoric, attention to temporality refers not only to the location of particular statements in the context of other statements, but also to the treatment of the concept of time itself (e.g. past, present, future) in persuasive discourse (Gill \& Whedbee, 1997). In Gadamer's hermeneutics, 'temporal distance' refers to the time that elapsed between the original production of the text and the time of hermeneutic interpretation (Palmer, 1969: 184-5).

From a structurational perspective, ${ }^{4}$ temporality is seen as a key aspect of textual context that influences the intended and received meaning of texts. A key idea is 'reversible time' which refers to the repetitive character of social life; 'time here is constituted only in repetition' (Giddens, 1984: 35). This conception of time is important in the structurational process because structures exist only as repeated manifestations in daily actions and as memory traces or interpretive schemes. This can afford a way of firstly identifying structural features of texts (whose structural nature is substantiated by virtue of their persistent manifestation in communicative actions by different agents in different contexts), and secondly of linking texts to wider social structures, since repeated central themes in texts have both cognitive and socialstructural correlates.

Paying attention to temporality in methodological terms, therefore, would necessitate that the analysis of communicative actions (seen as textual 'fragments' or as constituents of texts that together with other texts constitute a discourse) should firstly take account of the timing of communicative actions as an aspect of textual context, and should secondly track texts and their contexts longitudinally, noting shifts over time in both and uncovering and theorizing their interconnections. As Giddens (1984: 142) has observed, 'no strip of interaction - even if it is plainly bracketed, temporally and spatially - can be understood on its own. M ost aspects of interaction are sedimented in time, and sense can be made of them only by considering their routinized, repetitive character'. (Discursive) structures are thus reproduced, replicated or plausibly challenged by (communicative) actions that are 
temporally recursive (that is, repeated continuously in time, as opposed to being one-off actions). An understanding of how communicative actions interact dialectically with discursive structures thus requires longitudinal monitoring of communicative actions and an exploration of their deep structures. A study of how temporally recursive communicative actions within an earlier period, for example, diffuse central themes, premises or assumptions in a social context that become aspects of deep structures at a later period (a structurational process between actions and structures), and how structures may resurface in communicative actions in particular situations requires longitudinal tracking of texts at these different levels of analysis.

With regard to the first analytical direction, the need to consider the temporal context of communicative actions, in the same way as a cultural artifact, can mean different things in different cultures (Schein, 1992); the meaning of a communicative action can vary in different (temporal) contexts. Taking into account the timing of a communicative action thus improves researchers' interpretations of what agents' first-order meanings are. The same utterance can have different meanings depending on when it was said and in what particular context; both in the micro-context of conversations, as studied in conversation analysis, but also in macro-contexts that change over longer time periods.

With regard to the second analytical direction, the need for longitudinal textual analyses is highlighted by the concept of 'reversible time'. A longitudinal analysis from a structurational perspective would focus on the extent to which a discourse (constituted by texts in turn constituted by communicative actions) exhibits shifting surface communicative actions and deep structures over time (these two being key analytical levels in the theory of structuration), and how these relate to textual context. In addition, it would focus on uncovering and theorizing the cognitive correlates of such discursive structures, the interpretive schemes in which such structures are enshrined, through which they manifest in communicative actions, and through which they acquire social significance by influencing agents' views of the world.

Lastly, a discourse analysis method based on a structurational view of discourse, by uncovering the structural features of discourse that are mostly unconscious, as well as their cognitive correlates in the form of interpretive schemes, can provide a way to access parts of agents' practical consciousness; what actors 'know' but cannot express explicitly except through patterns in their (communicative) actions that are manifestations of these aspects of practical consciousness. This conception does not resort to deterministic concepts of structure, but acknowledges that such structures both constrain and also enable agents by providing resources for social interaction and private 
reflection that agents draw on: the concept of 'duality of structure' in structuration theory. M ore importantly, it provides the conceptual basis and the liberating potential for social change, by emphasizing the dynamic process by which structures are formed but also potentially altered and re-formed through social interaction.

\section{Notes}

1 For useful outlines of the theory of structuration, please see Thompson (1989), Bryant and Jary (1991), and Jones (1999).

2 See particularly 'Structuralism and the theory of the subject' in Giddens (1979: 9-48), and 'Structuralism, post-structuralism and the production of culture' in Giddens (1987: 73-108). Even though there are important differences between the structuralist and poststructuralist traditions, Giddens's original critique has focused on issues that are arguably common in both traditions, for example, the privileging of written text over spoken discourse and the consequent neglect of textual context and human agency. For clarity of exposition, we refer only to the structuralist tradition in the next section.

3 The issue of subjectivity has been directly and extensively addressed mainly from a critical perspective (e.g. K nights \& Willmott, 1989; Willmott, 1997; Parker, 1999); our discussion below does not aim to go into detail on issues of subjectivity, but rather to indicate how a structurational perspective can help us to think about the discourse-subject relationship in non-singular terms.

$4 \quad$ Giddens referred to time as 'perhaps the most enigmatic feature of human experience' (1984: 34). He developed concepts such as time-space distantiation, time-space edges, and world-time, which he integrated in his theory of structuration. Here, we address one aspect of Giddens's theorizing on time, the concept of reversible time, which is more relevant to the analysis of discourse.

\section{References}

Alvesson, M . O rganizations as rhetoric: Knowledge-intensive firms and the struggle with ambiguity. Journal of M anagement Studies, 1993, 30, 997-1015.

Archer, M.S. Culture and agency: The place of culture in social theory, 2nd edition. Cambridge: Cambridge University Press, 1996.

A ristotle $\mathrm{O} \mathrm{n}$ rhetoric. Translated by G.A. Kennedy. Oxford: Oxford University Press, 1991.

Atkinson, P. Ethnomethodology: A critical review. Annual Review of Sociology, $1988,14,441-65$.

Austin, J.L. How to do things with words. Oxford: Oxford University Press, 1961. 
Barley, S.R. Semiotics and the study of occupational and organizational cultures. Administrative Science Q uarterly, 1983, 23, 393-413.

Barley, S.R. \& Tolbert, P.S. Institutionalization and structuration: Studying the links between action and institution. O rganization Studies, 1997, 18, 93-117.

Barrett, F.J ., Thomas, G.F. \& H ocevar, S.P. The central role of discourse in largescale change: A social construction perspective. Journal of A pplied Behavioral Science, 1995, 31, 352-72.

Barry, D. \& Elmes, M. Strategy retold: Toward a narrative view of strategic discourse. Academy of M anagement Review, 1997, 22, 429-52.

Barthes, R. Image, music, text. London: Fontana, 1977.

Barthes, R. The semiotic challenge. Berkeley, CA: University of California Press, 1994.

Bartlett, F.C. Remembering. Cambridge: Cambridge University Press, 1932.

Bartunek, J.M. Changing interpretive schemes and organizational restructuring: The example of a religious order. Administrative Science Q uarterly, 1984, 29, 355-72.

Bartunek, J.M . \& M och, M .K. First-order, second-order, and third-order change and organizational development interventions: A cognitive approach. Journal of Applied Behavioral Science, 1987, 3, 483-500.

Bateson, G. Steps to an ecology of mind. London: Intertext, 1972.

Berger, P. \& Luckmann, T. The social construction of reality. London: Penguin, 1966.

Bhaskar, R. The possibility of naturalism: A philosophical critique of the contemporary human sciences. Brighton: $\mathrm{H}$ arvester, 1979.

Bloom, A.H. The linguistic shaping of thought. A study on the impact of thinking in China and the West. H illsdale, N J: Erlbaum, 1981.

Blumer, H. Society as symbolic interaction. In J.G. M anis and B.N . M eltzer (Eds), Symbolic interaction: A reader in social psychology. Boston, M A: Allyn and Bacon, 1970, pp. 139-48.

Boje, D.M. The storytelling organization: A study of story performance in an office-supply firm. A dministrative Science Q uarterly, 1991, 36, 106-26.

Boland, R.J., Jr Accounting and the interpretive act. Accounting, 0 rganizations and Society, 1993, 18(2/3), 125-46.

Boland, R.J., Jr Why shared meanings have no place in structuration theory: A reply to Scapens and $M$ acintosh. Accounting, O rganizations and Society, 1996, 21(7/8), 691-7.

Bougon, M., Weick, K.\& Binkhorst, D. Cognition in organizations: An analysis of the Utrecht jazz orchestra. Administrative Science Q uarterly, 1977, 22, 607-39.

Bourdieu, P. O utline of a theory of practice. Translated by R. N ice. Cambridge: Cambridge University Press, 1977.

Boyce, M.E. Collective centering and collective sense-making in the stories and storytelling of one organization. Organization Studies, 1995, 16(1), 107-37.

Bryant, C.G.A.\& Jary, D. (Eds) Giddens' theory of structuration: A critical appraisal. London: Routledge, 1991.

Burgoon, M., H unsaker, F.G. \& Dawson, E.J. Human communication, 3rd edition. London: Sage, 1994. 
Burrell, G. \& M organ, G. Sociological paradigms and organizational analysis. Aldershot: Gower, 1979.

Byrne, R. Power-knowledge and social theory in the systematic misrepresentation of contemporary French social theory in the work of Anthony Giddens. In C.G.A. Bryant and D. Jary (Eds), Giddens' theory of structuration: A critical appraisal. London: Routledge, 1991.

Callinicos, A. Anthony Giddens: A contemporary critique. Theory \& Society, 1985, 14, 133-66.

Chilton, P. \& Ilyin, M . M etaphor in political discourse: The case of the 'common European house'. Discourse \& Society, 1993, 4(1), 7-31.

Cicourel, A.V. Three models of discourse analysis: The role of social structure. D iscourse Processes, 1981, 3, 101-31.

Cleary, C. \& Packard, T. The use of metaphors in organizational assessment and change. G roup \& O rganization M anagement, 1992, 17, 229-41.

Crider, C. \& Cirillo, L. Systems of interpretation and the function of metaphor. Journal for the Theory of Social Behavior, 1991, 21, 171-95.

Daft, R.L. \& Wiginton, J.C. Language and organization. Academy of M anagement Review, 1979, 4, 179-91.

Dandridge, T.C., M itroff, I. \& Joyce, W.F. O rganizational symbolism: A topic to expand organizational analysis. Academy of Management Review, 1980, $5,77-82$.

DeSanctis, G. \& Poole, M.S. Capturing the complexity in advanced technology use: Adaptive structuration theory. O rganization Science, 1994, 5, 121- 47.

de Saussure, F. Course in general linguistics. London: D uckworth, 1983.

Donnellon, A. Language and communication in organizations: Bridging cognition and behavior. In H.P. Sims, Jr \& D.A. Gioia (Eds), The thinking organization. San Francisco, CA: Jossey-Bass, 1986, pp. 137-64.

Donnellon, A., Gray, B. \& Bougon, M.G. Communication, meaning and organized action. Administrative Science Q uarterly, 1986, 31, 43-55.

Dougherty, D. Interpretive barriers to successful product innovation in large firms. O rganization Science, 1992, 3, 179-202.

du Gay, P. \& Salaman, G. The cult(ure) of the customer. Journal of M anagement Studies, 1992, 29, 615-33.

du Gay, P., Salaman, G. \& R ees, B. The conduct of management and the management of conduct: Contemporary managerial discourse and the constitution of the 'competent' manager. Journal of Management Studies, 1996, 33, 263-82.

Eden, C. O n the nature of cognitive maps. J ournal of M anagement Studies, 1992, 29, 261-5.

Edwards, D. D iscourse and cognition. London: Sage, 1997.

Eoyang, C. Symbolic transformation of belief systems. In L.R. Pondy, P.J. Frost, G. M organ and T.C. Dandridge (Eds), O rganizational symbolism. Greenwich, CT: JAI Press, 1983, pp. 109-21.

Evered, R. The language of organizations: The case of the navy. In L.R. Pondy, P.J . Frost, G. M organ and T.C. Dandridge (Eds), O rganizational symbolism. Greenwich, CT: JAI Press, 1983, pp. 109-21.

Eysenck, M.W. Principles of cognitive psychology. H ove: Erlbaum, 1993. 
Fairclough, N. Discourse and text: Linguistic and intertextual analysis within discourse analysis. D iscourse \& Society, 1992, 3, 193-217.

Festinger, L. A theory of cognitive dissonance. London: Tavistock, 1959.

Fiol, C.M . A semiotic analysis of corporate language: O rganizational boundaries and joint venturing. Administrative Science Q uarterly, 1989, 34, 277-303.

Ford, J.D. \& Ford, L.W. The role of conversations in producing intentional change in organizations. Academy of Management Review, 1995, 20, 541-70.

Foucault, M. Politics and the study of discourse. In G. Burchell, C. Gordon and P. M iller (Eds), The Foucault effect: Studies in governmentality. London: $\mathrm{H}$ arvester Wheatsheaf, 1968/1991, pp. 53-72.

Foucault, M. The archaeology of knowledge. London: Routledge, 1972.

Foucault, M . Power/know ledge: Selected interview s and other writings, 1972-77. N ew York: Pantheon, 1980.

Frake, C.O. H ow to ask for a drink in Subanun. A merican A nthropologist, 1964, 66(6), 127-32.

Freundlieb, D. Foucault's theory of discourse and human agency. In C. Jones and R. Porter (Eds), Reassessing Foucault: Power, medicine and the body. London: Routledge, 1994, pp. 152-80.

Gadacz, R.R. Agency, unlimited. Canadian Journal of Political and Social Theory, 1987, 11, 158-63.

Garfinkel, H. Studies in Ethnomethodology. Englew ood Cliffs, N J : Prentice H all, 1967.

Garnsey, E. \& Rees, B. Discourse and enactment: Gender inequality in text and context. H uman Relations, 1996, 49, 1041-64.

Geertz, C. The interpretation of cultures. N ew York: Basic Books, 1973.

Gephart, R.P. The textual approach: Risk and blame in disaster sensemaking. Academy of M anagement Journal, 1993, 36, 1465-514.

Gersick, C. Revolutionary change theories: M ultilevel exploration of the punctuated equilibrium paradigm. A cademy of $M$ anagement R eview, 1991, 16, 10-36.

Giddens, A. Central problems in social theory. London: M acmillan, 1979.

Giddens, A. The constitution of society. Cambridge: Polity, 1984.

Giddens, A. Social theory and modern sociology. Cambridge: Polity, 1987.

Giddens, A. N ew rules of sociological method, 2nd edition. Stanford, CA: Stanford University Press, 1993.

Gill, A.M .\& Whedbee, K. R hetoric. In T.A. van Dijk (Ed.), D iscourse studies: A multidisciplinary introduction, Vol. 1. Thousand Oaks, CA: Sage, 1997, pp. 157-83.

Gioia, D.A. Symbols, scripts and sensemaking: Creating meaning in the organizational experience. In H.P. Sims, Jr and D.A. Gioia (Eds), The thinking organization. San Francisco, CA: J ossey-Bass, 1986a, pp. 49-74.

Gioia, D.A. The state of the art in organizational social cognition: A personal view. In H .P. Sims, Jr and D.A. Gioia (Eds), The thinking organization. San Francisco, CA: Jossey-Bass, 1986b, pp. 336-56.

Goffman, E. The neglected situation. In P.P. Giglioli (Ed.), Language and social context. London: Penguin, 1972, pp. 61-6.

Grant, D., Keenoy, T. \& O swick, C. Organizational discourse: Of diversity, 
dichotomy and multi-disciplinarity. In D. Grant, T. Keenoy and C. O swick (Eds), D iscourse and organization. London: Sage, 1998, pp. 1-13.

Gray, B., Bougon, M.G. \& Donnellon, A. Organizations as constructions and destructions of meaning. Journal of M anagement, 1985, 11(2), 77-92.

H ansen, C.D. \& Kahnweiler, W.M. Storytelling: An instrument for understanding the dynamics of corporate relationships. H uman Relations, 1993, 46, 1391-409.

H arré, R. \& Gillett, G. The discursive mind. Thousand O aks, CA: Sage, 1994.

$\mathrm{H}$ atch, $\mathrm{M}$.J. Irony and the social construction of contradiction in the humor of a management team. O rganization Science, 1997, 8, 275-88.

$\mathrm{H}$ ead, H. A phasia and kindred disorders of speech. Cambridge: Cambridge University Press, 1926.

Held, D. \& Thompson, J.B. (Eds) Social theory of modern societies: Anthony Giddens and his critics. Cambridge: Cambridge University Press, 1989.

$\mathrm{H}$ endry, J. Strategic decision making, strategy and social practice. Journal of $M$ anagement Studies, forthcoming, 37.

$\mathrm{H}$ ofstede, $\mathrm{G}$. The interaction between national and organizational value systems. Journal of Management Studies, 1985, 22, 347-57.

Hopkins, N . \& Reicher, S. Social movement rhetoric and the social psychology of collective action: A case study of anti-abortion mobilization. Human Relations, 1997, 50, 261-86.

H uff, A.S. Mapping strategic thought. Chichester: Wiley, 1990.

Johnson, G. Strategic change and the management process. Oxford: Blackwell, 1987.

Johnson, G. M anaging strategic change: The role of symbolic action. British J ournal of M anagement, 1990, 1, 183-200.

Jones, M. Structuration theory. In W. Currie and R. Galliers (Eds), Rethinking management information systems. Oxford: O xford University Press, 1999, pp. 103-35.

Kamoche, $\mathrm{K}$. R hetoric, ritualism and totemism in human resource management. H uman Relations, 1995, 48, 367-85.

Keenoy, T. H uman resource management: Rhetoric, reality and contradiction. International J ournal of H uman R esource M anagement, 1990, 1, 363-84.

Keenoy, T., O swick, C.\& Grant, D. O rganizational discourses: Text and context. O rganization, 1997, 4, 147-57.

Kets de Vries, M .F.R. \& M iller, D. Interpreting organizational texts. Journal of M anagement Studies, 1987, 24, 233-47.

Kilduff, M. Deconstructing organizations. Academy of Management Review, 1993, 18, 13-27.

Knights, D. \& M organ, G. Corporate strategy, organizations and subjectivity: A critique. O rganization Studies, 1991, 12, 251-73.

Knights, D. \& M organ, G. Strategy under the microscope: Strategic management and IT in financial services. Journal of M anagement Studies, 1995, 32, 191-214.

Knights, D.\& Willmott, H. Power and subjectivity at work: From degradation to subjugation in social relations. Sociology, 1989, 23, 535-58.

Lakoff, G. \& Johnson, M. M etaphors we live by. Chicago: Chicago University Press, 1980. 
Layder, D. Key issues in structuration theory: Some critical remarks. Current Perspectives in Social Theory, 1987, 8, 25-46.

Lewin, K. Field theory in social science. London: Tavistock, 1952.

Liedtka, J.M . \& Rosenblum, J.W. Shaping conversations: M aking strategy, managing change. California M anagement Review, 1996, 39(1), 141-57.

Light, D., Jr Surface data and deep structure: O bserving the organization of professional training. Administrative Science Q uarterly, 1979, 24, 551-61.

Louis, M .R. O rganizations as culture-bearing milieux. In L.R. Pondy, P.J . Frost, G. M organ and T.C. Dandridge (Eds), O rganizational symbolism. Greenwich, CT: JAI Press, 1983, pp. 39-54.

M cCann, C.D.\& H iggins, E.T. Social cognition and communication. In H. Giles and W.P. Robinson (Eds), Handbook of language and social psychology. Chichester: Wiley, 1990, pp. 13-32.

M acintosh, N.B. \& Scapens, R.W. Structuration theory in management accounting. Accounting, O rganizations and Society, 1990, 15, 455-77.

$M$ alinowski, B. The context of situation. In G.P. Stone and H .A. Faberman (Eds), Social psychology through symbolic interaction. Toronto: $\mathrm{X}$ erox College Publishing, 1970, pp. 158-60.

$M$ anning, P.K. M etaphors of the field: Varieties of organizational discourse. Administrative Science Q uarterly, 1979, 24, 660-71.

$M$ anning, P.K. \& Cullum-Swan, B. N arrative, content, and semiotic analysis. In N.K. Denzin and Y.S. Lincoln (Eds), $\mathrm{H}$ andbook of qualitative research. Thousand Oaks, CA: Sage, 1994, pp. 463-77.

$M$ arshak, R.J. M anaging the metaphors of change. O rganizational Dynamics, 1993, 22, 44-56.

M artin, J. \& Powers, M.E. Truth or corporate propaganda: The value of a good war story. In L.R. Pondy, P.J. Frost, G. M organ and T.C. D andridge (Eds), O rganizational symbolism. Greenwich, CT: JAI Press, 1983, pp. 93-107.

M estrovic, S.G . Anthony G iddens: The last modernist. London: R outledge, 1998. M organ, G. Paradigms, metaphor and puzzle solving in organization theory. Administrative Science Q uarterly, 1980, 25, 660-71.

M organ, G. M ore on metaphor: Why we cannot control tropes in administrative science. Administrative Science Q uarterly, 1983, 28, 601-7.

M organ, G.\& Ramirez, R. A ction learning: A holographic metaphor for guiding social change. Human Relations, 1983, 37, 1-28.

M oscovici, S. O n social representations. In J.P. Forgas (Ed.), Social cognition: Perspectives on everyday understanding. London: A cademic Press, 1981, pp. 181-209.

M umby, D.K.\& Clair, R.P. O rganizational discourse. In T.A. van Dijk (Ed.), D iscourse as social interaction. London: Sage, 1997, pp. 181-205.

M umby, D.K.\& Stohl, C. Power and discourse in organization studies: Absence and the dialectic of control. Discourse and Society, 1991, 2, 313-32.

$\mathrm{N}$ oorderhaven, $\mathrm{N}$. The argumentational texture of transaction cost economics. O rganization Studies, 1995, 16, 605-23.

0 'Connor, E.S. Paradoxes of participation: Textual analysis and organizational change. O rganization Studies, 1995, 16, 769-803.

O rlikowski, W.J.\& Yates, J. Genre repertoire: The structuring of communicative 
practices in organizations. Administrative Science Q uarterly, 1994, 39, 541-74.

Ortony, A. M etaphor and Thought. Cambridge: Cambridge University Press, 1979.

O swick, C., Keenoy, T. \& Grant, D. M anagerial discourses: Words speak louder than actions? Journal of A pplied M anagement Studies, 1997, 6, 5-12.

Palmer, R.E. H ermeneutics. Evanston, IL: N orthw estern University Press, 1969.

Parker, M. Capitalism, subjectivity and ethics: Debating labour process analysis. O rganization Studies, 1999, 20, 25-45.

Pettigrew, A.M. On studying organizational cultures. Administrative Science Q uarterly, 1979, 24, 570-81.

Petty, R.E. \& Cacioppo, J.T. The elaboration likelihood model of persuasion. In L. Berkowitz (Ed.), Advances in experimental social psychology, 19. O rlando, FL: Academic Press, 1986, pp. 123-205.

Phillips, N.\& Brown, J.L. Analyzing communication in and around organizations: A critical hermeneutic approach. A cademy of M anagement J ournal, 1993, 36, 1547-76.

Pomerantz, A. \& Fehr, B.J. Conversation analysis: An approach to the study of social action as sense making practices. In T.A. van Dijk (Ed.), D iscourse as social interaction. London: Sage, 1997, pp. 64-91.

Pondy, L.R. Leadership as a language game. In M.W. M CCall, Jr. and M.M. Lombardo (Eds), L eadership: Where else can we go? Durham, N C: Duke University Press, 1978, pp. 87-101.

Pondy, L.R. The role of metaphors and myths in organization and the facilitation of change. In L.R. Pondy, P.J. Frost, G. M organ and T.C. Dandridge (Eds), O rganizational symbolism. Greenwich, CT: JAI Press, 1983, pp. 157-66.

Pondy, L.R. \& M itroff, I.I. Beyond open systems of organization. Research in O rganizational Behavior, 1979, 1, 3-39.

Pondy, L.R., Frost, P.J., M organ, G. \& Dandridge, T.C. (Eds) O rganizational symbolism. Greenwich, CT: JAI Press, 1983.

Putnam, L.L., Phillips, N. \& Chapman, P. M etaphors of communication and organization. In S.R. Clegg, C. H ardy and W.R. N ord (Eds), H andbook of organization studies. London: Sage, 1996, pp. 375-408.

Ranson, S., Hinings, B. \& Greenwood, R. The structuring of organizational structures. Administrative Science Q uarterly, 1980, 25, 1-17.

Ricoeur, P. What is a text? Explanation and understanding. In D. Rasmussen (Ed.), Mythic-symbolic language and philosophical anthropology. The H ague: M artinus Nijhoff, 1971, pp. 135-50.

Ricoeur, P. From text to action. Evanston, IL: N orthwestern University Press, 1991.

Riley, P. A structurationist account of political culture. Administrative Science Q uarterly, 1983, 28, 314-37.

Rodrigues, S.B. \& Collinson, D.L. 'H aving fun?' H umor as resistance in Brazil. O rganization Studies, 1995, 16, 739-68.

R umelhart, D.E. Schemata and the cognitive system. In R.S. Wyer, Jr. \& T.K. Srull (Eds), Handbook of social cognition. Hillsdale, NJ: Erlbaum, 1984, pp. 161-88. 
Sackmann, S. The role of metaphors in organization transformation. Human Relations, 1989, 42, 463-85.

Saferstein, B. Collective cognition and collaborative work: The effects of cognitive and communicative processes on the organization of television production. Discourse and Society, 1992, 3, 61-86.

Sarason, Y. A model of organizational transformation: The incorporation of organizational identity into a structuration theory framew ork. A cademy of M anagement Best Papers Proceedings, 1995, 47-51.

Scapens, R.W. \& M acintosh, N.B. Structure and agency in management accounting research: A response to Boland's interpretive act. Accounting, 0 rganizations and Society, 1996, 21, 675-90.

Schein, E. O rganizational culture and leadership, 2nd edition. San Francisco, CA : Jossey-Bass, 1992.

Schon, D.A. Generative metaphor. A perspective on problem-setting in social policy. In A. O rtony (Ed.), M etaphor and thought. Cambridge: Cambridge University Press, 1979, pp. 254-83.

Schultz, M. Transitions between symbolic domains in organizations. O rganization Studies, 1991, 12, 489-506.

Silverman, D. The theory of organizations. London: H einemann, 1970.

Smircich, L. Organizations as shared meanings. In L.R. Pondy, P.J. Frost, G. M organ and T.C. Dandridge (Eds), O rganizational symbolism. Greenwich, CT: JAI Press, 1983, pp. 55-65.

Taylor, S.E. \& Crocker, J. Schematic bases of social information processing. In E.T. H iggins, C.P. Herman and M .P. Z anna (Eds), Social cognition. H illsdale, NJ: Erlbaum, 1981, pp. 89-134.

Thachankary, T. Organizations as 'texts': Hermeneutics as a model for understanding organizational change. Research in O rganization Change and D evelopment, 1992, 6, 197-233.

Thomas, W.I. \& Thomas, D.S. Situations defined as real are real in their consequences. In G.P. Stone and H.A. Faberman (Eds), Social psychology through symbolic interaction. Toronto: X erox College Publishing, 1970, pp. 154-6.

Thompson, J.B. The theory of structuration. In D. H eld and J.B. Thompson (Eds), Social theory of modern societies: Anthony Giddens and his critics. Cambridge: Cambridge University Press, 1989, pp. 56-76.

Tsoukas, $H$. The missing link: A transformational view of metaphors in organizational science. A cademy of M anagement Review, 1991, 16, 566-85.

Tsoukas, H. Analogical reasoning and knowledge generation in organization theory. O rganization Studies, 1993, 14, 323-46.

van Dijk, T.A. Social cognition, social power and social discourse. Text, 1988, 8, 129-57.

van Dijk, T.A. Principles of critical discourse analysis. D iscourse and Society, 1993, 4, 249-83.

van Dijk, T.A. The study of discourse. In T.A. van Dijk (Ed.), D iscourse as structure and process. London: Sage, 1997, pp. 1-34.

van $\mathrm{M}$ aanen, J. O bservations on the making of policemen. $\mathrm{H}$ uman $\mathrm{O}$ rganization, 1973, 32, 407-18. 
van $\mathrm{M}$ aanen, $\mathrm{J}$. The fact of fiction in organizational ethnography. Administrative Science Q uarterly, 1979, 24, 539-50.

Watson, T.J. Rhetoric, discourse and argument in organizational sense making: A reflexive tale. O rganization Studies, 1995, 16, 805-21.

Weaver, G.R. \& Gioia, D.A. Paradigms lost: Incommensurability vs structurationist inquiry. O rganization Studies, 1994, 15, 565-90.

Weber, M. The nature of social action. In W.G. Runciman (Ed.), Weber: selections in translation. Cambridge: Cambridge University Press, 1991, pp. 7-32.

Weick, K. Enactment processes in organizations. In B.M. Staw and G.R. Salancik (Eds), New directions in organizational behavior. Chicago, IL: St Clair Press, 1977, pp. 267-300.

Weick, K. Cognitive processes in organizations. Research in O rganizational Behavior, 1979, 1, 41-74.

Westley, F. \& M intzberg, H. Visionary leadership and strategic management. Strategic M anagement Journal, 1989, 10, 17-32.

Westley, F. \& Vredenburg, H. The perils of precision: $M$ anaging global tensions to achieve local goals. Journal of Applied Behavioral Science, 1996, 32, 143-59.

Whittington, R. Putting Giddens into action: Social systems and managerial agency. Journal of M anagement Studies, 1992, 29, 693-712.

Whittington, R. Social structures and strategic leadership. In J. Hendry, G. Johnson and J. N ewton (Eds), Strategic thinking: Leadership and the management of change. Chichester: Wiley, 1993, pp. 181-97.

Willmott, $H$. The structuring of organizational structure: A note. Administrative Science Q uarterly, 1981, 26, 470-4.

Willmott, H. Unconscious sources of motivation in the theory of the subject: An exploration and critique of Giddens' dualistic models of action and personality. Journal for the Theory of Social Behavior, 1986, 16, 105-21.

Willmott, $\mathrm{H}$. Rethinking management and managerial work: Capitalism, control and subjectivity. H uman R elations, 1997, 50, 1329-59.

Wodak, R. Discourse analysis: Problems, findings, perspectives. Text, 1990, 10, 125-32.

$\mathrm{Xu}$, S. Argumentation, explanation, and social cognition. Text, 1992, 12, 263-91.

Yates, J. \& O rlikowski, W.J. Genres of organizational communication: A structurational approach to studying communication and media. Academy of M anagement Review, 1992, 17, 299-326.

Zald, M.N. M ore fragmentation? Unfinished business in linking the social sciences and the humanities. Administrative Science Q uarterly, 1996, 41, 251-61. 
Loizos Heracleous is a Lecturer in Strategic Management at Trinity College, University of D ublin. He earned his PhD in Management Studies from the Judge Institute of $M$ anagement Studies, U niversity of $C$ ambridge. $\mathrm{He}$ conducts research within the broad areas of strategic management, organizational change and development, and organization theory. $\mathrm{H}$ is work has appeared in academic and practitioner journals, and he serves as a member of the editorial board of the Asia Pacific Journal of Management.

[E-mail: heraclel@ tcd.ie]

John Hendry is a University Lecturer in Management Studies at the Judge Institute of Management Studies and a Fellow of Girton College, both at the University of C ambridge. He holds a PhD from the U niversity of London and served on the faculties of London Business School and Cranfield School of Management before moving to Cambridge in 1990 as Founder Director of the University of Cambridge MBA program. His current research focus is on the sociology of ethics in business.

[E-mail: j.hendry@ jims.cam.ac.uk] 